\title{
Territorialidades campesinas. Los "puestos" en el oeste de La Pampa (Argentina) ${ }^{1}$
}

\author{
María Eugenia Comerci²
}

\begin{abstract}
RESUMEN
En la Argentina contemporánea, la nueva expansión capitalista hacia espacios "de borde" pone en jaque la capacidad de reproducción campesina. El artículo indaga acerca de la territorialidad campesina en base a dos estudios de caso localizados en el oeste de La Pampa. Se analizan elementos materiales y simbólicos de la configuración territorial de los "puestos" teniendo como foco las condiciones materiales de existencia, la organización interna y los patrones de distribución de los asentamientos rurales de La Humada y Chos Malal. Asimismo se abordan cómo afecta a la dinámica territorial campesina la reciente expansión del capital a través del cercado de los espacios de pastoreo y cuáles son las territorialidades emergentes en contextos de avance capitalista. De este modo, desde una perspectiva diacrónica y con metodología cualitativa, se plantean los cambios y las continuidades en la configuración de los puestos campesinos en contextos de conflictividad emergente.
\end{abstract}

Palabras clave: Territorialidades, Campesinado, Puestos, La Pampa.

\begin{abstract}
In contemporary Argentina, the new capitalist expansion spaces "edge" threatens the ability of peasant reproduction. The article inquires about the peasant territoriality based on two case studies located in the west of La Pampa. Material and symbolic elements of the territorial configuration of the "stalls" are analyzed, focusing the material conditions of existence, the internal organization and distribution patterns of rural settlements of La Humada and Chos Malal. It also addresses how it affects the rural territorial dynamics the recent expansion of capital through the fencing and grazing spaces which are emerging in contexts territorialities capitalist advance. Thus, from a diachronic perspective and qualitative methodology, changes and continuities in the configuration of the peasants put in the context of emerging conflicts arise.
\end{abstract}

Key words: Territoriality, Peasantry, Puestos, La Pampa.

Las reflexiones de este trabajo se enmarcan en los proyectos de investigación en los que participa la autora, en calidad de directora y codirectora, desarrollados en el Programa "Geografías de La Pampa: dinámicas, conflictos y sinergias multiterritoriales", dirigido por la Mg. Beatriz Dillon en el período (2013-2017). Programa de investigación con evaluación externa aprobado por el Consejo Directivo (Resolución 038-13), Facultad de Ciencias Humanas, Instituto y Departamento de Geografía de Universidad Nacional de La Pampa, Argentina. Artículo recibido el $1^{\circ}$ de diciembre de 2015, aceptado el 16 de marzo de 2017 y corregido el 28 marzo de 2017

CONICET-Universidad Nacional de La Pampa (Argentina).E-mail: eugeniacomerci@gmail.com 
La "Travesía" se ubica en el centro de Argentina en plena diagonal árida, más precisamente, en los cinco departamentos del oeste de la provincia de La Pampa. Este sector, dominado por el monte occidental, abarca más de un tercio de la superficie provincial y participa de forma periférica en el conjunto de la población, con sólo el $4,6 \%$ del total de los habitantes. El espacio se caracteriza por la aridez de su ambiente, la presencia pequeñas localidades y más de quinientos "puestos" distribuidos en la zona rural. Los puestos constituyen la unidad de residencia familiar de los puesteros, no siempre fija a un sitio, pues las pasturas pueden cambiar con el transcurso de los años o, taparse las aguadas y relocalizarse las viviendas rurales en otro sector del campo. La denominación de los puestos está asociada con la presencia de recursos en el lugar, situaciones vividas o deseadas por sus dueños o, incluso, historias generadas en esos sitios. Estos topónimos expresan la fuerte vinculación de los productores con el entorno natural y el sofisticado conocimiento popular de la flora, fauna, hidrología y geomorfología regional.

Los "puesteros/ras" en esta región de la Argentina son los productores familiares, crianceros, con perfil campesino que habitan en el puesto, residen y trabajan en su unidad productiva, cualquiera sea su relación jurídica con la tierra (propietarios, poseedores o apareceros precarios). Desde comienzos del siglo XX hasta fines de la década de 1990, los grupos domésticos de las zonas rurales de La Humada y Chos Malal (ver figura No 1) sustentaban su existencia mediante el desarrollo de una producción de subsistencia basada en el uso compartido del monte. Las tierras eran fiscales o propiedad de privados ausentistas que habían comprado los títulos a precios irrisorios en la bolsa de valores de Buenos Aires y Londres a fines del siglo XIX y luego de las campañas militares contra los pueblos originarios. La falta de valorización de las desiertas tierras con monte bajo no atrajeron ni capitales, ni asentamientos de los titulares registrales, pero sí se poblaron de indígenas y criollos que aprovecharon los manantiales y buenas pasturas existentes en el lugar, dando origen a diversos puestos.

La puesta en ejecución de algunas políticas públicas hacia la década del setenta, lentamente redefinieron las prácticas y los mecanismos de articulación de los puesteros con el mercado incrementando la mercantilización de los intercambios de los campesinos (ganado, abono, artesanías en telar). En las décadas del setenta, ochenta y noventa, desde el Estado se promovieron algunas actividades productivas que modificaron las condiciones de vida y la dinámica interna de los puestos (Comerci, 2012a). Esas actividades se realizaron, durante muchos años en "campos abiertos", de allí el término Travesía que alude a grandes extensiones de tierra, con poca presencia de ganado y de habitantes, sin alambrado y escasas aguadas. Sin embargo, en los últimos quince años (2000-2015), ante la revalorización de los espacios de borde y el avance de nuevos agentes con lógicas territoriales de tipo empresarial, los campesinos están redefiniendo sus prácticas productivas-reproductivas y las relaciones sociales. La fuerte demanda de tierras valorizadas especialmente para la ganadería vacuna, relocalizada del sector oriental donde avanzó la sojización, promovió el interés inmobiliario por los campos, acciones de compra-venta, el cercado perimetral de los predios, y con ello, una nueva configuración regional en la Travesía y en la dinámica interna de los puestos.

En la actualidad, extensos espacios de tierras áridas de Argentina permiten el desarrollo de economías domésticas de tipo pastoril para las cuales el acceso y control de los recursos naturales comportan elementos de primer orden de importancia en términos de su reproducción social. La expansión del capitalismo hacia territorios antes no valorizados, ejerce presión sobre el campesinado, creando serias dificultades para garantizar la supervivencia (Comerci, 2012a; 
Bendini y Steimbreger, 2013; Torres et al., 2014). En este marco en el artículo se indaga sobre la territorialidad campesina en contextos de expansión de la frontera productiva, en base a dos casos en el oeste de La Pampa (Argentina). Cabe interrogarse: ¿cuáles son los elementos materiales y simbólicos que configuran territorialmente los "puestos" campesinos?, ¿cuáles han sido, a través del tiempo, las condiciones materiales de existencia de las familias rurales, la organización interna de los puestos y los patrones de distribución de los asentamientos rurales del oeste de La Pampa, específicamente en La Humada y Chos Malal?, ¿cómo afecta a la dinámica territorial campesina la reciente expansión del capital a través del cercado de los espacios de pastoreo? y ¿cuáles son las territorialidades emergentes en contextos de avance capitalista? Desde una perspectiva diacrónica se abordan los cambios y las continuidades en la configuración de los puestos en contextos de expansión del capital, así como también las relaciones de poder-resistencia expresadas en territorialidades internas que suponen la existencia de espacios de control, influencia y dominio de ciertos grupos.

Desde el punto de vista metodológico, se considera a la investigación cualitativa desde la perspectiva constructivista, pues centra su interés en la forma en que el mundo social es comprendido, experimentado y producido. Tiene en cuenta los contextos témporo-espaciales, la perspectiva de los sujetos y se nutre de una amplia variedad de métodos, flexibles y sensibles al mundo social, que facilitan la reflexión, interpretación e inducción con rigurosidad, sistematicidad y creatividad (Vasilachis, 2003).

Figura $\mathrm{N}^{\circ} 1$

Localización de las áreas de estudio

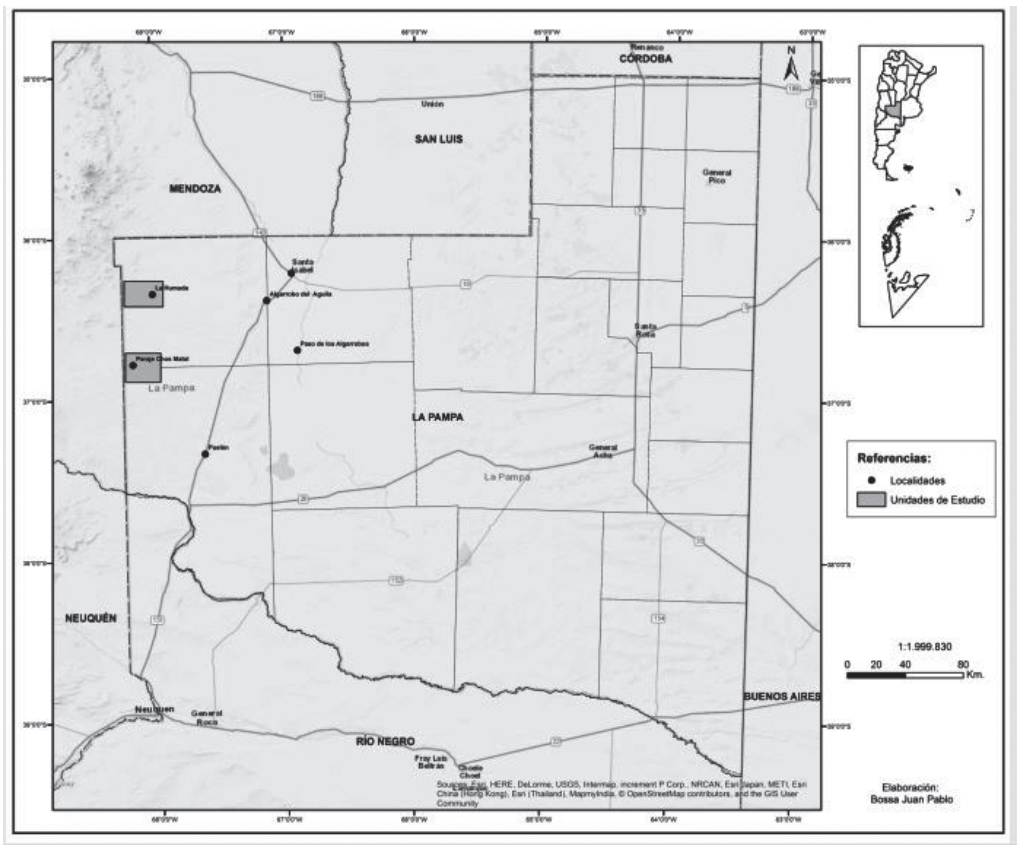

Fuente: Elaboración propia. Mapa diseñado por Juan Pablo Bossa (2017) basado en datos del Instituto Geográfico Nacional, Dirección General de Catastro y Dirección de Vialidad, Provincia de La Pampa. 
Para el desarrollo del trabajo se recuperaron distintos testimonios obtenidos en entrevistas en profundidad realizadas en los puestos de los parajes Chos Malal y La Humada (véase Figura $N^{\circ} 1$ ) en los años 2007, 2008, 2009 y 2013 y a informantes clave en la ciudad de Santa Rosa en el año 2016. Se realizó un muestreo teórico para descubrir las categorías y sus propiedades, dado que posibilita ampliar o reducir potencialmente los conceptos. En este sentido, el investigador reconstruye y analiza la información en un proceso que se encuentra controlado por la teoría emergente. Se trata de un muestreo flexible que se adecua durante la investigación y se reformula de acuerdo con la capacidad de incorporar o restringir las categorías o la teoría. Además se utilizaron diversas fuentes documentales tales como informes eclesiásticos, informes técnicos, cartografía e imágenes del archivo histórico para reconstruir la configuración del espacio en el pasado y triangular con la información proporcionada en los relatos.

A continuación se plantean los lineamientos teóricos que guían el trabajo y luego las transformaciones territoriales generadas en la unidad de estudio. Posteriormente se abordan los factores que inciden en la localización de los puestos analizados y la configuración interna (material-simbólica) de estos espacios. En este marco se desarrollan los distintos métodos de construcción de las casas y algunas representaciones a través del tiempo; los elementos que conforman el espacio peridoméstico y la nueva dinámica gestada en el "monte abierto" en el contexto de expansión del capital y avance de la propiedad privada.

\section{Espacio y territorio en clave relacional}

El espacio y el territorio son constitutivos de nuestra propia existencia ya sea en su dimensión físico-biológica como en la simbólico-social. Se concibe al espacio como una categoría abstracta, inclusiva e integradora que constituye una dimensión de la vida social. Es la "materialización de la existencia humana" (Lefevbre, 1986), pero también expresa aspectos simbólicos que aluden a la representación y a los imaginarios. Como señala F. Ordoñez (2011), el espacio geográfico comprende un todo multidimensional, al referirse no sólo a determinadas condiciones ambientales, sino también a relaciones sociales. Cuando la mirada está puesta en los escenarios de poder, nos remitimos al concepto de territorio. El concepto de territorio es una categoría -en cierta formaambigua, que adquirió diferentes significados a través del tiempo: desde concepciones clásicas que lo asociaban con las secciones del espacio ocupado por individuos, grupos o instituciones del Estado moderno, a definiciones que lo relacionan con el poder social-simbólico de un grupo por el control del espacio. El territorio construido a partir de esta perspectiva relacional, se encuentra inserto en las relaciones socio-históricas y de poder.

Desde este enfoque la construcción de territorios supone, para R. Sack, (1986), materializar determinadas relaciones de poder en torno al control de un área. Como señala R. Haesbaert (2004) una noción de territorio que desprecie su dimensión simbólica está predestinada a comprender apenas una parte de los complejos meandros de los lazos entre espacio y poder. El poder no puede quedarse escindido en una lectura materialista, sino debe entenderse en un sentido relacional. El poder envuelve relaciones sociales, pero también las representaciones que ellas vinculan y producen. De este modo, el concepto de territorio, desde esta perspectiva relacional, supone la existencia de un espacio dominado, controlado y apropiado por un grupo que ejerce poder (material-simbólico) y el control en una determinada área de influencia (Comerci, 2015). Así concebidos, los territorios se vuelven ámbitos generadores de raíces e identidades legitimadas 
por un grupo y asociadas con un espacio concreto, que puede ser continuo o discontinuo, articulado por una trama de redes que actúan en la interescalaridad. La territorialidad se gesta cuando un grupo ejerce el control y apropiación de un espacio con cierta temporalidad. Como señala C. Raffestin (1980), la territorialidad, tiene un valor particular, ya que refleja la multidimensionalidad de la vivencia territorial por parte de los miembros de una colectividad. De este modo, en un mismo territorio, pueden existir múltiples territorialidades.

Estas categorías permiten explicar la conformación de espacios apropiados y controlados por ciertos grupos en determinados momentos históricos, así como también los conflictos en las relaciones de poder expresados en el control y la delimitación de ciertas áreas de influencia, que supone la conformación de territorialidades. De esta forma, por ejemplo, el Territorio Nacional de La Pampa Central, excluido de la Gobernación de la Patagonia en 1882 y luego de ser mensurado y amojonado, se dividió en veintiséis fracciones, que luego darían lugar a los departamentos, secciones, fracciones, lotes y parcelas, geométricamente divididos en cuadros. El espacio (concebido como un "desierto") luego de las campañas militares contra los pueblos originarios, comenzó a ser mensurado, cartografiado y comercializado en el mercado de tierras (Comerci, 2015).

La Geografía -al servicio del poder- reprodujo esta espacialidad abstracta, geométrica, lineal y uniforme mediante la cartografía oficial física y catastral. Al mismo tiempo que se construían representaciones sobre los distintos sectores que integraban el nuevo territorio occidental que lentamente se poblaba de puesteros, el Estado nacional intervenía con acciones concretas en el espacio. Diferentes agentes e instituciones, mediante la ejecución de distintas políticas públicas, buscaron articular el oeste con el este pampeano. No obstante esta territorialidad dominada desde el poder, coexistió con otras, irregulares y singulares, creadas por los campesinos, habitantes de estos espacios que se explorarán en este trabajo.

En las últimas décadas la renovación conceptual alcanzó también a la categoría analítica de lugar, entendido como un espacio apropiado por un grupo -independientemente de la escala que se use- al que ciertos sujetos le atribuyen valores que se vuelven objeto de construcción simbólica (Agnew, 1987). Ese espacio, además de la carga emotiva atribuida por quienes lo construyen, forma parte de un todo más amplio y es permeable a los diversos procesos que se desarrollan regionalmente. Los lugares están saturados de significados y sentidos, pero poseen una dimensión material, existencial; se relacionan con el espacio concreto y con unos atributos definidos históricamente de carácter dinámico. El habla popular expresada en los nombres de los lugares proporciona saberes retrospectivos de situaciones del pasado de esos sitios. De esta forma, la toponimia de los parajes rurales se encuentra atravesada por relaciones de poder en las que algunos sujetos, en determinados contextos históricos, construyeron ciertas representaciones sobre el lugar, mediante diversas denominaciones y con diferentes sentidos (Comerci, 2012a).

Los nombres de los lugares contribuyen a producir imaginarios espaciales. El habla popular, el conocimiento del lugar y sus recursos naturales así como la apropiación del espacio, han tendido una doble expresión (material-simbólica) en los puestos y formado parte de las prácticas territoriales que contribuyen a la reproducción social de los campesinos. Los puestos del oeste pampeano se encuentran saturados de significados y sentidos $y$, al mismo tiempo, poseen una dimensión material-existencial, se relacionan con un espacio concreto y con unos atributos definidos históricamente. Los nombres de los espacios de vida de los grupos domésticos también se asocian al entorno en el que desarrollan sus relaciones y varían regionalmente, según se trate del 
ambiente de las mesetas occidentales o de la depresión fluvial. Definidas las categorías analíticas, a continuación, se realiza una breve descripción de las unidades de estudio para luego avanzar con la organización interna de los puestos.

\section{Persistencia y cambio en el espacio occidental de La Pampa}

En el espacio occidental de La Pampa, en la etapa previa a la conformación del Estado nacional, las sociedades indígenas nómades valorizaron y explotaron el jarillal. El uso y la apropiación de los recursos que proveía el monte, unido a un profundo conocimiento del lugar, posibilitaron la supervivencia de los grupos, el dominio de ciertos espacios y la conformación de áreas de influencia. Las territorialidades indígenas se vinculaban con la posición estratégica de este lugar en la región y con el desarrollo de distintas prácticas de intercambio con los grupos andinos y de los llanos (pampeanos). Por otro lado, esas territorialidades poseían una lógica interna, materializada en una densa red de rastrilladas que articulaban nodos (manantiales y zonas altas), que permitían el aprovisionamiento temporal de recursos y el control local del espacio.

Una vez culminadas las campañas -de 1879- contra los pueblos originarios, se buscó integrar los espacios en dominio indígena con el conjunto nacional. Este proceso marcó una nueva fase en la estructuración territorial, que generó una ruptura con la preexistente. El control del espacio, supuso la creación de un nuevo territorio, expresado en una cartografía catastral. Al igual que en otros Territorios Nacionales, no sólo se buscó controlar material y simbólicamente estos espacios, sino también integrarlos al "dinámico y pujante" conjunto pampeano, desdibujando las históricas redes sociales y de intercambio con la región cuyana-andina.

Mientras se vendían las tierras y cambiaban los titulares registrales que tomaban estos campos como mera inversión inmobiliaria de bajo costo, el monte se comenzó a repoblar con indígenas y criollos que se fueron asentando en las aguadas naturales de los "campos libres", y pusieron en acción distintas estrategias productivas-reproductivas asociadas con la cría de ganado, la caza de ganado silvestre, la elaboración de artesanías en telar y cuero, el uso de recursos locales para la construcción de viviendas, refugios y corrales, entre otros (Comerci, 2010). Se conformaron redes familiares, vecinales. En este marco, los agentes ambulantes abastecían de insumos y compraban la producción.

La zona donde actualmente se emplaza el paraje Chos Malal (Figura $\left.N^{\circ} 2\right)$, por su posición en la región y la presencia de distintos recursos naturales, fue "parada" indígena antes de la conformación del Estado nacional. De la misma manera, la zona de La Humada (Figura $N^{\circ} 3$ ) fue transitada por pueblos originarios dada la presencia de una laguna y su posición estratégica entre los cerros Agua de Torres y Chicalcó.

A través del siglo XX, las familias garantizaron su reproducción mediante la combinación de distintas prácticas y del desarrollo de una producción de subsistencia basada en el uso compartido del monte (entre grupos de familias), que posibilitaba la caza de fauna silvestre, la recolección, la cría de ganado caprino, ovino o equino y el trabajo del tejido de la lana y del cuero. La conformación del Estado provincial, desde 1951, promovió el desarrollo de distintas políticas públicas 
Figura $\mathrm{N}^{\circ} 2$

Puestos y recursos en Chos Malal

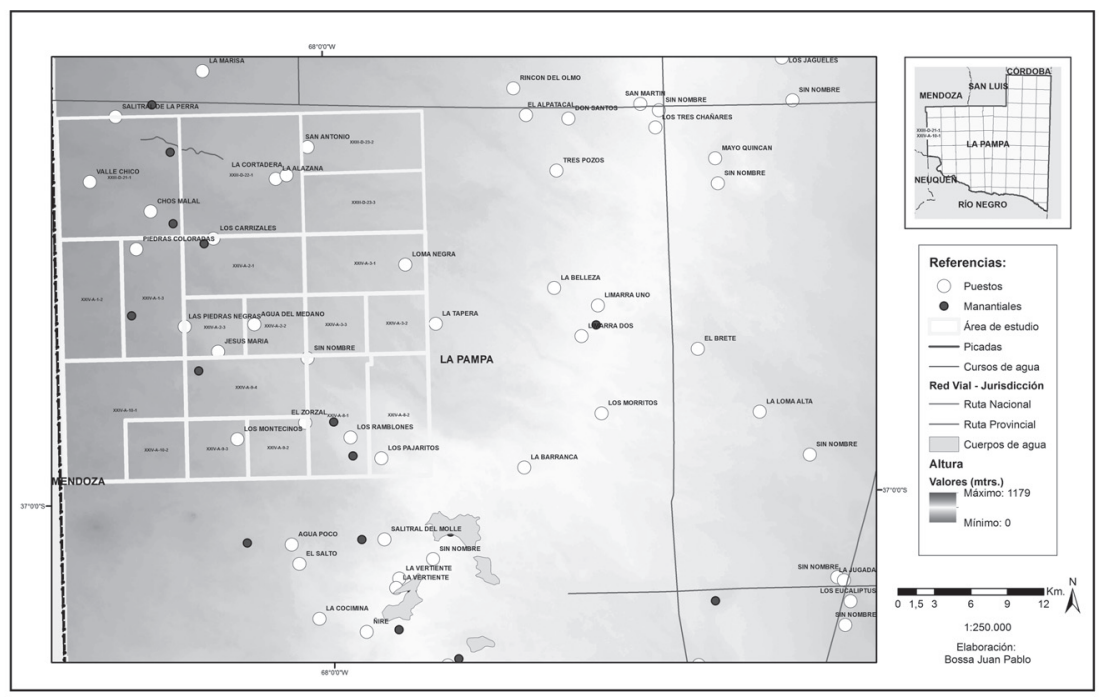

Fuente: Elaboración propia. Mapa diseñado por Juan Pablo Bossa (2017) basado en datos del Instituto Geográfico Nacional, Dirección General de Catastro y Dirección de Vialidad, Provincia de La Pampa.

Figura $\mathrm{N}^{\circ} 3$

Puestos y recursos en La Humada

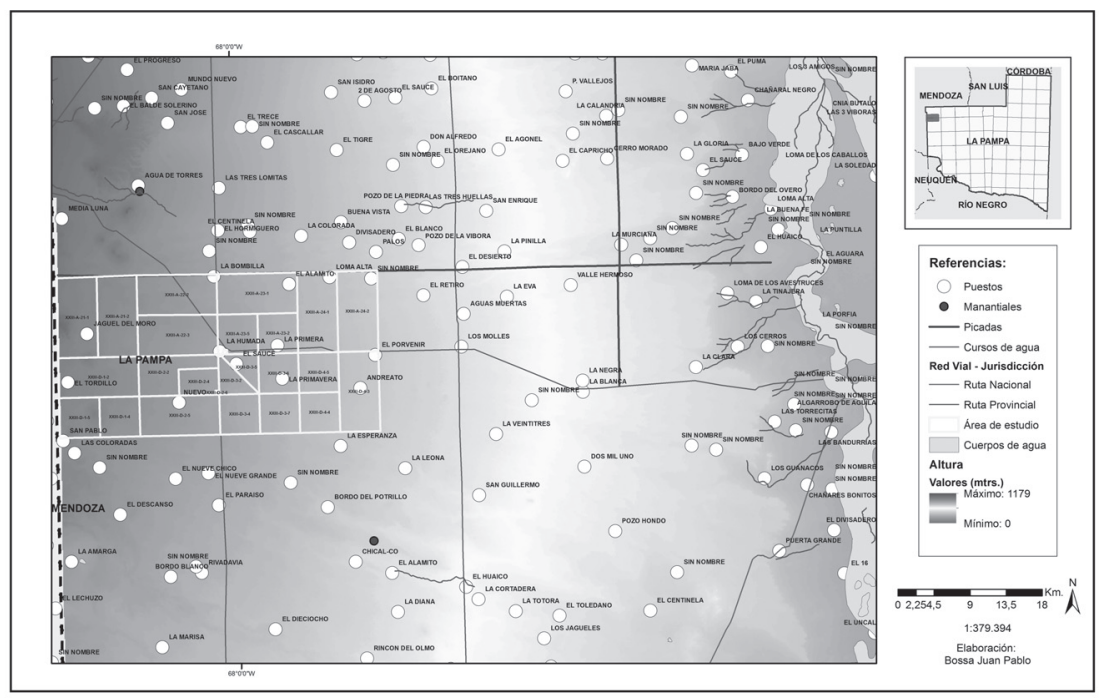

Fuente: Elaboración propia. Mapa diseñado por Juan Pablo Bossa (2017) basado en datos del Instituto Geográfico Nacional, Dirección General de Catastro y Dirección de Vialidad, Provincia de La Pampa. 
que fortalecieron la actividad artesanal y ganadera reorientándola al mercado. A su vez, estas políticas fomentaron el uso del dinero, en el marco de un proceso de integración subordinada del extremo oeste al resto de la provincia.

Desde la década del setenta, a medida que los grupos domésticos se ampliaban por crecimiento natural y las nuevas generaciones se establecían en la zona, comenzaron a restringirse los campos libres. En el caso de La Humada, muchas familias llevaron a cabo acciones judiciales (como la prescripción adquisitiva por la ley veinteñal) para acceder a la propiedad privada de la tierra en la que ejercían actos posesorios. La presencia de campos fiscales e influencia de instituciones socializadoras (como la escuela de La Humada y la Comisión de Fomento), así como también la situación socioeconómica de los productores, posibilitaron el acceso a la propiedad privada y/o sucesión de las familias de este lugar. De este modo, se comenzó a realizar un dominio privado de los recursos mediante vías formales y jurídicas, mientras en Chos Malal persistió el uso común del espacio de pastoreo y la ocupación de hecho.

A fines de la década del ochenta, predominaban usos y apropiaciones privadas del espacio en La Humada, delimitado generalmente con alambre perimetral. Dentro de las familias ampliadas, se utilizaban -no obstante- ciertos espacios de forma común (el de pastoreo y peridoméstico), manteniendo cada generación su propia vivienda. La instalación del alambrado perimetral y la gradual disminución de los campos fiscales en La Humada lentamente fueron restringiendo la movilidad de las familias en busca de nuevos campos libres, así como también disminuyeron las actividades de caza y recolección. En el conjunto de los puestos se configuraba espacialmente un damero de explotaciones cercadas perimetralmente que, con el paso de los años, se fue densificando.

En el caso de Chos Malal cuatro factores posibilitaron -no sin amenazas de desalojos- formas de apropiación colectivas del espacio: la posesión "de hecho" de la tierra, la presencia de fuertes redes familiares, el trabajo comunitario preexistente en diferentes actividades, unidas a la falta de interés de explotación de los campos por parte de los titulares registrales. Los grupos domésticos fueron valorizando y apropiándose -material y simbólica- de los recursos del lugar, dando origen a espacios diferenciados bajo el control de familias agrupadas (y extendidas) que compartían un espacio de pastoreo (Comerci, 2012a). Esta particular distribución de los campos y forma de apropiación de hecho (no jurídica, informal) y colectiva del espacio, desarrollada desde hace más de un siglo, gestó una territorialidad se está desarticulando ante el avance de un alambrado en los últimos veinte años y la emergencia de los conflictos por la tierra entre los poseedores puesteros (más del $90 \%$ en Chos Malal y del $30 \%$ en La Humada) y los titulares registrales.

La valorización del espacio occidental se ha generado, no sólo con las prácticas productivas sino también con el avance de la propiedad privada de productores capitalizados y empresas sobre puesteros. En la configuración de la tenencia de la tierra interdepartamental, la mayor cantidad de explotaciones con propiedad o sucesión indivisa y arrendamiento se concentra en las jurisdicciones del este de La Pampa, mientras los departamentos centro-occidentales (Chalileo, Chicalcó, Puelén, Limay Mahuida y Curacó) son los que más explotaciones con ocupación tienen. Como consecuencia del proceso de expansión de la frontera numerosos conflictos se han generado en estos departamentos entre los titulares registrales y los productores poseedores, que han derivado en despojos de familias, en actos de violencia directa, con intervención del estado provincial mediante la promulgación de leyes que suspenden temporalmente los desalojos (Comerci, 2012b). 
En el caso de estudio, las inversiones de empresas petroleras, forestales y ganaderos están produciendo el cierre de caminos irregulares (huellas) que unen puestos y ojos de agua. En este escenario, en los últimos quince años han emergido conflictos entre vecinos y con agentes extralocales así como nuevas formas de sociabilidad entre puesteros/as que recuperan prácticas de organización comunitaria realizadas en el pasado. Los productores ganaderos que acceden a la propiedad de la tierra, provenientes de las provincias de Córdoba, Mendoza, Buenos Aires o del este de La Pampa, con lógicas territoriales distintas a la de los puesteros, cercan sus propiedades con alambre perimetral, desdibujando los circuitos de pastoreo caprino y cerrando caminos internos. Ponen los campos en producción con ganado vacuno de cría y contratan mano de obra asalariada encargada de la explotación. Generalmente sobrecargan los campos con vacunos dado que desconocen la receptividad del campo pues provienen de zonas con mayores precipitaciones. Establecen pocos vínculos con sus vecinos y visitan esporádicamente la "estancia" pues no residen en la unidad productiva. Los nuevos asentamientos, se diferencian de los preexistentes por llamarse "estancias", no puestos y presentan denominaciones variadas que aún no son expresadas en toda la cartografía.

Como luego se desarrollará, la revalorización de la zona repercute en las subjetividades campesinas en las que aparece el temor y la preocupación por el futuro de las familias en el lugar y, asimismo, redefine las relaciones de poder entre los vecinos y con productores extralocales. En este contexto, además de las prácticas productivas se están produciendo acciones colectivas para acceder a la propiedad privada de la tierra de los campos pastoriles compartidos y, de esta forma, garantizar la continuidad en el lugar. A pesar de estos conflictos, en el año 2015, vivían 36 familias distribuidas en forma dispersa en el paraje Chos Malal y unas 20 en la zona de La Humada (si se excluye la población agrupada del pueblo). Los grupos domésticos llevan a cabo distintas actividades y prácticas que dan cuenta de la diversidad de fuentes de ingresos, la complementariedad de la producción ganadera con la artesanal y la particular relación que establecen con el entorno. Además de la cría de ganado caprino, vacuno y equino de forma extensiva, algunas familias elaboran artesanías (en tejido de telar y en soga) para consumo y/o venta, practican la caza de zorro, piche, avestruz y recolectan especies del monte para leña o para la realización de tinturas naturales, infusiones y remedios caseros.

Los campesinos complementan sus ingresos con trabajo -por lo general, masculino- extrapredial, con remesas o con ingresos provenientes desde el Estado (vía microcréditos, subsidios, cajas de comida, pensiones, entre otros). En los últimos años (2011-2015), la importancia de los recursos monetarios extraprediales obtenidos desde el Estado nacional a través de distintas transferencias (asignaciones familiares, pensiones, jubilaciones, entre otras), ha sido muy significativa. A continuación abordamos la configuración regional de estos asentamientos campesinos.

\section{Los puestos a escala regional y sus patrones de distribución}

Por lo general, los puestos del oeste pampeano se encuentran agrupados en determinados lugares o se distancian en extensiones que varían entre uno y diez kilómetros. En los cuatro departamentos del oeste provincial (Chicalcó, Puelen, Chalileo y Limay Mahuida) se registran 523 puestos, muchos de ellos, hoy deshabitados (Figura $\mathrm{N}^{\circ} 4$ ). 
Figura $\mathrm{N}^{\circ} 4$

Configuración de los puestos en el oeste de La Pampa (Argentina)

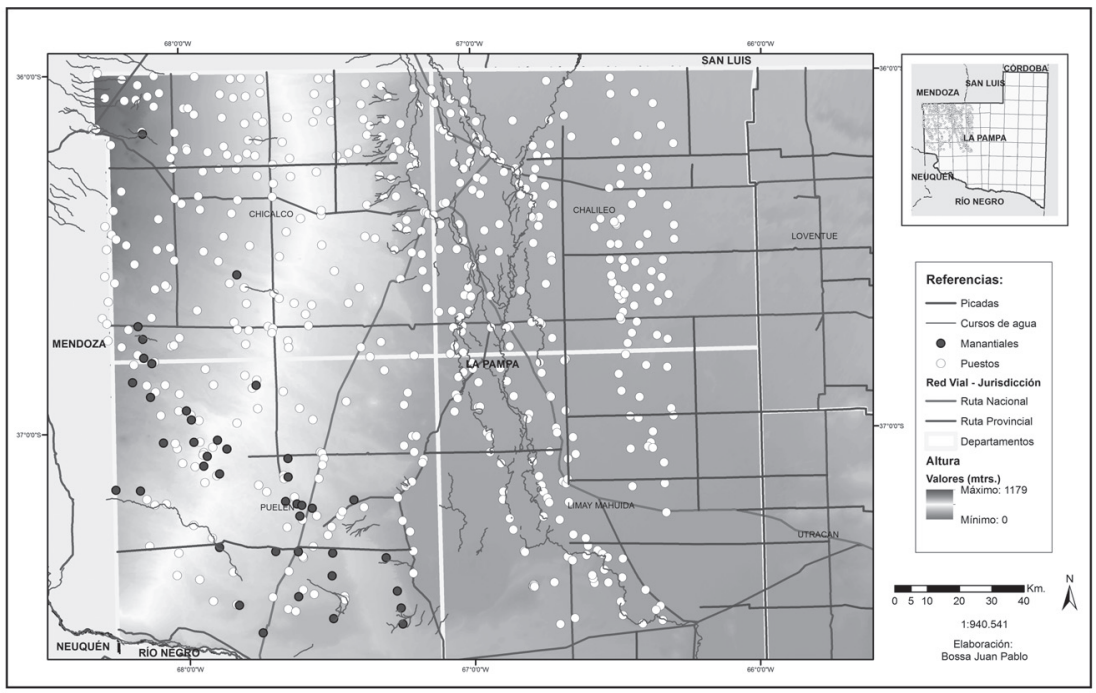

Fuente: Elaboración propia. Mapa diseñado por Juan Pablo Bossa (2017) basado en datos del Instituto Geográfico Nacional, Dirección General de Catastro y Dirección de Vialidad, Provincia de La Pampa.

Su particular distribución en el espacio es producto de los lazos familiares, la relación jurídica con la tierra, la valorización social de los recursos naturales locales (aguadas naturales, pasturas y monte) y la cercanía de picadas y/o cruces de caminos (Comerci, 2010). Estos factores se han identificado en la zona de estudio pero también en otros espacios del oeste pampeano (tales como Algarrobo del Águila, Paso de la Esperanza, La Puntilla, Colonia Emilio Mitre, Paso Maroma, entre otros) y del sur mendocino (Agua Escondida, La Salinilla). Sin embargo, si se amplía la escala de análisis, se observan algunas diferencias entre los dos casos de estudio.

Las denominaciones de los puestos o topónimos de las unidades de estudio se han referido a través del tiempo, por lo general, a recursos naturales locales geomorfológicos, hidrológicos, fitogeográficos o zoológicos, o a situaciones vividas, imaginadas o deseadas por los puesteros/ras. Sin dudas los elementos del paisaje imprimen ciertos rasgos, en general físicos, a los nombres de los puestos y parajes. En el caos de estudio si bien aparecen algunos nombres en mapuche (Trapalcó o Chos Malal) referidos a recursos, no es común el uso de toponimias indígenas. Mientras en Chos Malal los nombres de los puestos/parajes se refieren mayoritariamente a recursos naturales del lugar (especies vegetales, colores con los que se identifican los pelajes de los animales, recursos hídricos o geoformas del relieve), en la zona de La Humada los nombres presentan una mayor diversidad refiriéndose a los recursos naturales, pero también a los apellidos de puesteros propietarios, aspectos religiosos (santos católicos), condiciones socioeconómicas predominantes (Comerci, 2012b).

En el paraje Chos Malal las densas redes de parentesco, el manejo común del espacio de pastoreo y la tenencia precaria de la tierra de los grupos domésticos permiten demarcar espacios 
de dominio y de control, donde se localizan ciertas familias. De este modo, pueden identificarse territorialidades internas, gestadas a partir de relaciones de poder entre los grupos domésticos. Al mismo tiempo, la localización de los puestos -al igual que en la organización espacial indígenacoincide con la presencia de ciertos recursos naturales valorados, tales como aguadas naturales, en bajos salitrosos y/o en "mallines" o campos húmedos, articulados por un denso trazado de huellas. Aquí la distribución de los puestos supone la conformación de territorialidades internas en las que confluyen algunos elementos aglutinantes expresados en la toponimia (con las denominaciones de los puestos Las Cortaderas, Los Carrizales, Los Rincones, entre otras).

La presencia de crianceros carentes de la propiedad de la tierra, no existe en la zona de La Humada. Allí, a medida que el grupo doméstico crece y entra en la fase de fisión o reemplazo, algunos de los hijos que deciden permanecer en la actividad y carecen de recursos económicos para comprar la tierra, se instalan en cercanías de la vivienda materna donde construyen la casa y suelen compartir algunos elementos del espacio peridoméstico (horno, baño, playón, corrales) y el espacio de pastoreo. Sin embargo los grupos domésticos no comparten, como en Chos Malal, un espacio de pastoreo común. De este modo, los asentamientos se encuentran localizados a 1 a 10 kilómetros de distancia, dando como resultado una organización espacial dispersa, similar a la de otros lugares del oeste pampeano, pero diferente a la de Chos Malal.

La gran mayoría de los puestos de este último paraje, localizados en la meseta basáltica, se sitúan en las zonas bajas cercanas a manantiales, mientras que en el caso de la pediplanicie, donde se ubica la zona de La Humada, la concentración de puestos se vincula con la presencia de mejores pasturas o bien la cercanía a las picadas y/o encrucijadas de huellas. Esta particular distribución de los asentamientos rurales actuales guarda relación con la localización de las paradas indígenas y posteriores valorizaciones de los recursos naturales.

A través del tiempo, el puesto ha constituido el asentamiento del grupo familiar. Como en otros espacios argentinos de la diagonal árida campesina, el eje central de la organización social y económica del espacio no es la comunidad, sino el grupo doméstico. En este marco, las familias son concebidas como las arenas centrales de producción, de distribución, de consumo y de reproducción social (Göbel, 2002). El espacio de control de cada familia es el puesto en cual se organiza en tres ambientes diferenciados: la vivienda o espacio doméstico, el espacio que rodea la casa o peridoméstico (Poduje, 2000) y el monte o campo abierto (véase Figura $N^{\circ} 5$ ). A los puestos se accede, generalmente mediante dos caminos irregulares o huellas que articulan los asentamientos dispersos y atraviesan los espacios de pastoreo.

Tanto la casa como el espacio que la rodea, asociados con el interior y el adentro, son ámbitos de dominio de la mujer. Por el contrario, el monte, o área donde se realiza el pastoreo de los animales, así como también las actividades de recolección y caza, es un espacio propiamente masculino. El monte y el espacio peridoméstico, constituyen ámbitos de uso colectivo, por el contrario las "casas" son espacio privados, internos, a los que tienen menor acceso los no residentes (Comerci, 2010). Estos tres espacios dan forma material-simbólica a los sistemas de producción agro-pastoril, los cuales "forman una intrincada red espacial, que evidencia no sólo la dispersión geográfica de los territorios de cada unidad de producción, sino también el emplazamiento de las mismas por el uso y tenencia comunal de la tierra y el agua, mecanismo que permitirá maximizar el uso de los recursos" (Hocsman, 2011: 76). A continuación desagregamos los espacios para analizar las particularidades de cada uno. 
Figura $N^{\circ} 5$

Croquis de elementos que conforman un puesto pampeano

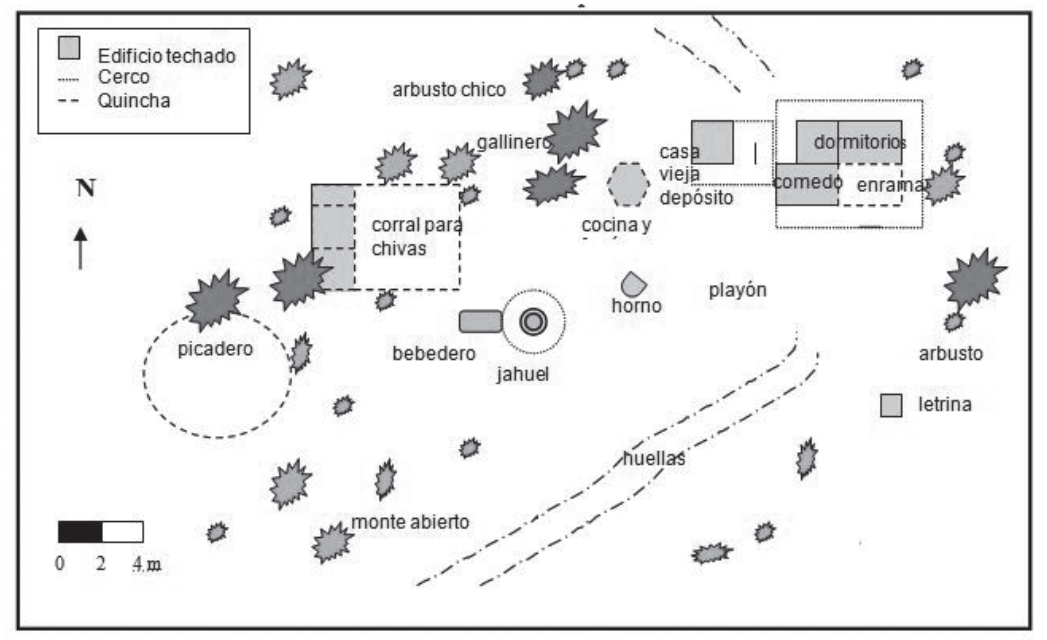

Fuente: Elaboración propia basado en datos obtenidos en el trabajo de campo

\section{Las casas: métodos de construcción y representaciones en perspectiva diacrónica}

El espacio doméstico integra la casa o "las casas", consta de un grupo de habitaciones y la galería o "enramada". Las distintas habitaciones que conforman las viviendas, suelen estar constituidas por un comedor, con pocos muebles donde se ubica una mesa rodeada por sillas, y en una de las paredes, se ubica la estufa hogar o una chimenea. El comedor puede estar comunicado o no con los dormitorios -que suelen ser uno y cuatro habitaciones- (Figura $N^{\circ} 4$ ) y constituyen el espacio interior. Dentro de la vivienda las mujeres realizan las actividades domésticas y trabajan con el huso/rueca o el telar. El desempeño de esta última práctica dentro del espacio doméstico permite la socialización de las niñas en el trabajo textil, la reproducción de ciertas relaciones de género, y el control de las demás actividades que debe realizar en ese lugar (cuidado de niños, aseo de la casa, preparación de comidas, etc.).

Como en el pasado, cada familia nuclear posee su propia "casita", si bien suele compartirse, entre distintas generaciones, la enramada o los elementos del espacio peridoméstico. Construir las "casas" (los puesteros suelen referirse, por lo general, en plural), lejos de ser una tarea sencilla, continúa implicando el trabajo conjunto de la familia y la puesta en acción de diferentes estrategias para la obtención de insumos. El análisis de los relatos orales de los entrevistados y trabajo de archivo permitió identificar cambios en las representaciones de los espacios, en los materiales con los que construían las viviendas y en la organización interna de las mismas a través del tiempo.

Testimonios de misioneros salesianos de 1925 identificaban en la vivienda en la zona de Chos Malal como la generadora de las enfermedades de los niños: 
"Los niños nacen en su mayoría raquíticos y a menudo con enfermedades graves. El origen se debe en gran parte a la vivienda que se reduce por lo general a un recoveco mal abrigado, cubierto de piedras y tierra. En él se hacinan todos los de la familia, por más numerosos que sean. Los hombres y jóvenes duermen casi todos afuera, en las prendas del recado, lo hacen para librarse de la terrible vinchuca que polula en el aposento" (Durando, 1925 en: Valla, 1998: 24-25).

En la Misión salesiana del año 1972, el párraco Mammana identificó 34 puestos y clasificó a las viviendas en dos tipos: de "enramada" y de "adobe". Dando continuidad a las representaciones salesianas de principio de siglo, la misión de la década del '70 caracterizaba a las viviendas como precarias y generadoras de enfermedades: "por lo general enramadas y viviendas de adobe dejan que desear la limpieza interior (viven en la tierra, las vinchucas abundan, faltan revoques, desinfección)" (Mammana, 1972). El informe registraba la cantidad de ambientes por vivienda, siendo más comunes las casas con dos y cuatro ambientes. Cabe mencionar que algunas viviendas de familias extendidas, alcanzaban a tener entre cinco y ochos ambientes, como puede observarse en el siguiente cuadro. Los misioneros salesianos, mediante políticas de "ayuda humanitaria", entregaban materiales exógenos a la zona que otorgaban nuevas fisonomías al puesto.

De acuerdo con testimonios de puesteros de La Humada y Chos Malal, hasta principios de 1990, las casas eran de ladrillo de adobe crudo y greda con techo de paja; de adobe unido con ramas de jarrilla, o de piedra y techo de paja picada. En algunos casos, se menciona que las viviendas tenían formas redondeadas y confluían en un playón central. Los muros -ya sea para los dormitorios, comedores o cocinas, se levantaban de cuatro formas (que se han identificado en otros parajes del oeste pampeano y sur mendocino):

- Con rocas de la zona (basalto y/o de granito) acomodadas y, en algunos casos unidas algún elemento ligante, por lo general, adobe o greda.

- Con ladrillos de adobe crudo, elaborados en moldes, por lo general, cajas de madera en las que se preparaba una masa de barro con pasto y guano que se dejaban secar al sol. El ladrillo crudo se ligaba con greda y, generalmente, se revocaba la pared con greda.

- Con "quincha", un entramado de ramas colocadas en forma vertical, atadas con alambre. Las ramas verticales se encontraban enterradas.

- Con "chorizos", es decir, se colocaban maderas y palos verticales de los se tendían alambres en forma horizontal y a los que luego se les agregaba en dirección opuesta pasto puna. Todo se compactaba con greda y /o adobe, que formaba una superficie lisa.

Las cubiertas o techos -a menudo a dos aguas y con unos $30 \mathrm{~cm}$ de pendiente- se preparaban palos, cañas y pasto puna ligado con barro y adobe. Solía ponerse por debajo una lona o naylon para evitar que las esporádicas precipitaciones y/o las nevadas los destruyeran. Eventualmente se incorporaban chapas y maderas. Lo usual en la carpintería estaba constituido por maderas obtenidas fuera de la zona, o bien, de jarilla.

Las familias solían combinar los métodos de preparación, en especial cuando iban a habitar viejos puestos cuyas paredes ya habían sido levantadas hasta un metro o metro y medio aproximadamente y se las continuaba armando con otros materiales más livianos (ladrillo de adobe, con adobe y paja o con método chorizo). De los cuatro tipos de casas, en Chos Malal eran más comu- 
nes los métodos de construcción con roca, "quincha" y "chorizo" y, en La Humada, predominaba el uso del ladrillo de adobe crudo.

En el pasado todas las casas eran autoconstruidas por los puesteros/ras, si bien participaba toda la familia en el proceso, los hombres eran los encargados de levantarla, mientras las mujeres hacían el trabajo de mantenerla constantemente, es decir, revocando las paredes greda y/o adobe y agregando ramas permanentemente. Las casas tradicionales se ampliaban a medida que crecía el grupo doméstico y solían estar separadas del resto del espacio por un cerco, llamado "guardaparque", construido con diversos materiales: palos y ramas, cañas, rocas, botellas, chapas o arbustos. En algunos casos la separación se realizaba con plantas adaptadas a la aridez, tales como los tamariscos o jarrillas. Este cercamiento de la casa, que continúa realizándose en la actualidad, permitía establecer un límite entre el adentro y el afuera, y evitaba que ingresen los animales al espacio doméstico. Existían entre uno y cuatro dormitorios, donde solían dormir en una cama común o un "cuerito" de oveja o chivo los niños menores. A menudo, en verano, los hombres solían dormir, en el espacio exterior, debajo de la enramada.

Como subyace en los siguientes relatos, en las representaciones sobre las viviendas se reiteran las asociaciones de las "casitas" (siempre en plural) con "refugios", "quinchos" o "ranchos":

"Las casas eran de piedra y barro... hechas medio redondas... Ahora si vas no conozco nada... están hechas de material...Ha cambiado muchísimo la vida de cómo era antes a ahora...No era una casa así cuadrada, que la podés cuadrar bien, y aparte que la hacían ellos nomás, mi papá, mi mamá, mis hermanas más grandes...La hermana que estaba ahí con ella y siempre estaba ahí...Hacían así las casitas...medio como tipo refugio para poder meterse...era nada más una piecita para todos... Después las demás eran de greda, no sé con qué otras cosas, jarilla" (criancera de la zona de La Humada, nacida en Chos Malal en 1982).

“Ante... las casas eran de jarilla...envarillada y con barro! Viste...en el techo le ponían nylon y le ponían yuyos y después embarrabas bien... En esas casas así se criaron todos... (criancera y artesana de Chos Malal nacida en 1947).

"El puesto primero, primero, eran unas casitas de adobe crudo... con barro nomás, y techo de caña con barro nomás... paja picada arriba, eran dos habitaciones nomás: una cocina y una habitación, ahí dormíamos todos nomás... mucho frío... lá'...frío, frío en la habitación" (criancero de La Humada, nacido en 1972).

Desde el inicio de la década del noventa, en ambas zonas, identificamos grandes transformaciones en las viviendas. Como ocurrió en otros espacios extrapampeanos con casas tradicionales (Göbel, 2002; Tomasi, 2005, 2009) las mayores relaciones con agentes extralocales, vínculos comerciales y aumento de la conectividad permitieron el acceso a materiales de origen industrial tales como ladrillos cocidos, chapas de aluminio y de cinc, cemento, plásticos, bloques de hormigón, madera enchapada, entre otros. La construcción se ha terciarizado, o bien, lo continúa haciendo algún familiar que "conoce" del proceso.

Al igual que las casas tradicionales, las viviendas nuevas cuentan con "enramadas" que consisten en galerías abiertas construidas con ramas, maderas o chapas en las que suele situarse una 
mesa rodeada por sillas y se desarrollan las actividades artesanales. La enramada sigue constituyendo un espacio de reunión especialmente utilizado en primavera y en verano. Suelen colgarse cueros y latas con preparaciones para curar enfermedades de los caprinos en las maderas vectoras del techo y, eventualmente, se las cierra con plásticos para reducir el viento.

En la zona de Chos Malal, la intervención del Estado provincial fue imprescindible y estratégica en la nueva organización del espacio doméstico. El estado nacional mediante el "Plan de Erradicación de Ranchos y el Mejoramiento habitacional" construyó, en 1990, 28 viviendas con paneles solares al lado de las casas viejas. Además de realizar periódicas fumigaciones en los corrales y demás construcciones de monte contra la enfermedad de Chagas, originada en la infección de la vinchuca, las casas que eran construidas con el método de "quincha" y "chorizo" fueron quemadas. Sólo quedaron en pie las viviendas con muro de piedra y las construidas con ladrillo de adobe, poco frecuentes en el paraje. Con el paso de los años, los crianceros volvieron a erguir las "casas de monte" como cocinas (con fogón), como depósito de materiales o como dormitorio de los abuelos, quienes preferían esos lugares dado que los consideraron más frescos.

Entre otras cuestiones, la nueva vivienda mejoró sustancialmente las condiciones de vida y reorganizó las actividades familiares ya que la posibilidad de acceder a luz eléctrica durante la noche permitía el desarrollo de las actividades artesanales y /o tareas domésticas. Sin embargo presenta una arquitectura poco adecuada para la zona, con una organización interna similar a las de los barrios planificados por el Estado en las ciudades. Las casas entregadas se constituían de tres habitaciones: una cocina-comedor, dos habitaciones y un baño interno. Asimismo, estaban dotadas de una galería, similar a las enramadas que, con el transcurso de los años, solían ser cerradas e incorporadas al espacio interior. Cada casa poseía, además, una cisterna para la obtención de agua llovida y una pantalla solar de 12 voltios, apta para electrificar las habitaciones. Los muros, construidos de ladrillo cocido y cemento, se entregaban revocados y pintados, con techos y aberturas de chapa, similares a las de los barrios urbanos del este de La Pampa.

Con el correr del tiempo, las familias realizaron reformas en la gran mayoría de las viviendas ya sea mediante la incorporación de galerías, estufas a carbón, el cierre de ventanas y puertas, o la generación de nuevas habitaciones. En muchos casos, cuando el Estado construyó la nueva vivienda (sólo en el caso de Chos Malal) lo hizo al costado de la vieja, la cual si era de monte fue quemada y si era de piedra permaneció utilizándose como vivienda de abuelos o hijos menores, o bien, como depósito de alimentos y/o herramientas.

En el caso de La Humada, algunos crianceros pudieron acceder a la compra de casas preexistentes, arreglaron la casa vieja, por lo general construida de adobe o de piedra. En otros casos, con ayuda de familiares y mucho esfuerzo levantaron una nueva vivienda. Los siguientes testimonios aluden a las diferentes formas de acceso a la construcción de las casas nuevas:

"Mi hermano hizo esto [la casa]... el que está en La Humada, es albañil... pero no nos alcanzó para revocar ni para el piso... tiene mucha idea para hacer (...) pero de a poco la vamos a arreglar" (criancera de la zona de la Humada nacida en 1974).

"Acá mismo estaba la casa de adobe. Se fue reformando. Así que... Eso sí, la casa se ha ido reformando, lo mismo que los guardaparques [también llamado "guardapatio", es el cerco que bordea a la casa] todo se ha ido reformando (...) Lo mismo que la modificación de la 
casa, la fui dándole forma que quedara con una sola puerta (...) antes eso lo pensaban, no lo ponían en cuenta. Si tenían que seguir haciendo tres piezas a la par" (productor de La Humada nacido en 1965).

"Esa tierra era de Montesinos era y nosotros compramos la asistencia, como le llamaban ellos, o sea la casa... entonces ellos se fueron... se fueron a una casa, no sé a dónde era... Tiene que haber sido en el '70 o en el sesenta y pico... y después a los pocos años, se fue a vivir la abuela, la madre de mi mamá... estuvo con nosotros hasta que falleció... Y por ahí siempre sabia estar un tío con la señora también... habían hecho un quincho aparte" (criancero de La Humada, nacido en 1972).

En la actualidad, las viviendas nuevas son rectas, simétricas, por lo general poseen integración de habitaciones, y están construidas con ladrillos cocidos y techo de chapa. Sólo en algunas familias con menos recursos continúan elaborándolas los integrantes del grupo doméstico. Cuando las construyen albañiles, las casas tienen una estructura con vigas que actúan previendo los movimientos sísmicos, como lo establece el código urbano del pueblo de La Humada.

Con respecto a la orientación de las viviendas de ambos espacios, suele relacionarse con los recursos de la zona (por ejemplo las casas se ubican frente a un salitral o una formación rocosa, o bien frente a un camino). Algunas casas están orientadas al oeste y otras al norte y al sur, pero no se puede identificar un patrón común.

\section{El espacio peridoméstico y el campo abierto}

Se denomina peridoméstico al espacio que se encuentra en el área de transición entre la vivienda y el monte. A diferencias de las viviendas, no se han encontrado demasiadas variaciones en la organización y composición de este sitio a través del tiempo. Se compone de diferentes construcciones que rodean la casa, constituidas por una cocina techada, el depósito, el sitio de provisión de agua, el horno de barro, la letrina, el gallinero, el playón, los corrales para caprinos, el picadero, y, eventualmente, bebedero, manga y brete para vacunos.

A diferencia de las casas que suelen poseer cada familia nuclear, en espacio peridoméstico es un ámbito colectivo compartido por diferentes generaciones dentro de las familias con estructura ampliada. Es decir, una familia compuesta por tres generaciones, suele tener tres casas pero comparten los elementos del espacio que rodea a las casas. Cada uno de ellos se organiza con una combinación de instalaciones y áreas de uso específico delimitadas territorialmente.

Entre los principales cambios a través del tiempo en el espacio peridoméstico, más que nuevas funciones en el uso del espacio, son los nuevos materiales con los que se construyen los corrales, picaderos, letrinas, entre otros (que incluyen el uso de madera, chapa, cemento o ladrillo cocido, caños petroleros, entre otros). En los últimos veinte años, mediante los créditos del Programa Social Agropecuario, subsidios del gobierno provincial y asesoramiento del Instituto Nacional de Tecnología Agropecuaria, se realizaron mejoras en los corrales mediante la incorporación de tablas de pino y la construcción de refugios para los caprinos. Otras transformaciones asociadas con el avance de la producción vacuna para cría -en la zona de La Humada- se expresan en la incorporación de mangas, bretes, bebederos, molinos y tanques australianos. 
El monte ha constituido a través del tiempo, un espacio de vida fundamental para la supervivencia de las familias. Este espacio, no sólo provee diferentes recursos (frutos, raíces, maderas, ramas y hojas) para la realización de infusiones, remedios caseros, tinturas naturales y/o combustión, sino también fauna silvestre (liebres, choiques, zorros o piches, entre otros), que posibilitan a los crianceros la realización de la caza de mamíferos silvestres y aves para el consumo doméstico o intercambio de pieles, cueros, plumas y/o huevos. Con muchos de los recursos que el monte ofrece los crianceros elaboran también diversas artesanías en telar, bordado y soga, ya sea para el consumo como para la venta. Las funciones que cumple actualmente el monte, son las mismas que se desarrollaban el pasado, de acuerdo con los distintos testimonios de los crianceros.

La escasa presencia de alambrados, si bien posibilita la obtención de diferentes recursos del monte y un manejo más sustentable de las pasturas, requiere de un control permanente de los animales y en caso de ser una familia pequeña, con escasa mano de obra, puede ocasionar la pérdida de los caprinos.

En La Humada, dado que el $70 \%$ de los productores son propietarios privados de los campos, es común el uso del campo de distintas generaciones dentro de la familia -cada una con su espacio doméstico-, así como cobrar por el pastoreo de ganado de terceros o bien tener animales a medias. Esos acuerdos entre las partes varían según las circunstancias y las necesidades del momento. En cambio en Chos Malal, donde predomina la tenencia precaria de la tierra (posesión de hecho) en más del $90 \%$ de los casos, existen espacios de pastoreo compartido, de los que diferentes familias hacen uso social del campo abierto. En estos casos, la delimitación de los campos actúa en planos simbólicos; existen zonas de pastoreo de cada familia dentro de ese espacio mayor compartido por todos. Los límites entre el área de influencia de una familia y otra, son relativamente flexibles y dinámicos. Por lo general, ciertos recursos naturales (lagunas, manantiales, afloramientos rocosos, bajos-salitrales) marcan las diferenciaciones de las áreas de influencia de cada grupo y bajo la denominación de esos recursos se identifica a la zona (por ejemplo en la zona de Piedras Coloradas, Los Rincones, Los Carrizales, entre otras). Este uso colectivo de la tierra interfamiliar, fue registrado por los misioneros salesianos en la década del setenta bajo la denominación de "tierras comunes":

"La generalidad de las mujeres y varones trabajan en tierras comunes que ellos consideran propias. Existe entre los pobladores una línea imaginaria entre lo común y "propio". Muchos consideran propio el lugar que pisan, ya que la posesión viene de padres a hijos, más allá de los 20 y 30 años. Jurídicamente les corresponde la posesión por prescripción veinteñal!!! Separan sus majadas para la pastura poniéndose de acuerdo (sin problemas en el uso común de los campos mejores). En esta zona se precisan entre 150 y 200 (hectáreas) de campo para un animal (sea este vacunos, caballares, mulares)" (Mammana, 1972:10).

El fragmento anterior expresa aspectos de la cosmovisión y las racionalidades de los sujetos en las que lo propio no estaba disociado de lo común, y además nos remite a los acuerdos entre vecinos por el uso del lugar y la apropiación-control del territorio. En el presente, la representación de la superficie de pastoreo en los crianceros/ras es radial y/o asimétrica pues el ganado genera un círculo en torno a la aguada y/o manantiales que existe en el campo. Los animales suelen "largarse" por la mañana en contra del viento para evitar la dispersión, o para el sector del campo que les corresponde. Es común que, cuando los animales se pasan a los campos de los vecinos, los crianceros acerquen la majada de chivos perdidos. Por la tarde suele salir el puestero a caballo a buscarlos si no regresan solos. 
Como ya se mencionó, en los últimos quince años, el avance del alambrado ha propiciado conflictos entre productores, una reducción de la superficie de pastoreo y una mayor presión sobre el monte. El achicamiento de los campos condiciona la cantidad de ganado por familia -y con ello la capacidad de absorción de mano de obra dentro de la unidad doméstica- es percibido de la siguiente manera por los campesinos: "Se han achicado los campos, han comprando alrededor, alrededor, alrededor [señalando], acá nomás pasa un alambre. Hay que ir hasta allá y pegar la vuelta" (productor de Chos Malal nacido en 1963).

Al cercado de los productores extralocales que compraron las tierras o bien valorizaron los títulos heredados e invirtieron en la actividad ganadera, se suma la división con alambre que lentamente comienzan a realizar los propios puesteros. En este sentido un técnico del Estado aducía lo siguiente en una entrevista realizada recientemente:

"Los puesteros del lugar también han cercado los campos y no hay lugar... eso es otro problema... no sólo los de afuera (...) Los de afuera los compran para bajo costo, compran 5000 hectáreas,...que en los papeles parecen mucho aunque es un desierto y después obtienen créditos importantes para otra actividad, tienen algunos animales y los trabajan... Algunos incorporaron tecnología, forrajes... Ahora está lleno de alambre, no podes pasar... Los de adentro, les quitan el espacio al resto" (Testimonio de coordinador de programas productivos).

En este contexto se han generado diversos conflictos y disputas por el acceso y uso de los recursos naturales.

\section{Nuevas territorialidades y conflictos}

La organización de los campos abiertos desarrollada desde hace más de un siglo, se está desarticulando ante el avance de un alambrado (y de la lógica territorial empresarial subyacente) que instaló un productor extralocal, que compró los derechos posesorios (de hecho) de un campesino que emigró a otra zona. El nuevo productor ocupó 2500 has, de las 20.000 fiscales en las que se concentra la mayor cantidad de puestos, y cercó el campo con alambrado perimetral. De este modo, avanzó sobre el espacio de pastoreo de otros puesteros. En este escenario, la imposibilidad de acceder al espacio de pastoreo para algunas familias produce tensiones y conflictos. La reducción de la superficie de pastoreo afecta especialmente al grupo de "Los Rincones", quienes se ven obligados a sobre-explotar que sector de monte que les queda.

Desde la percepción de los crianceros de ambos espacios de estudio, el proceso de cambio más claro en la zona se manifiesta en el avance de los "alambres" sobre los "campos libres" y la "llegada" de "gente de afuera", "nuevos dueños" que los "encierra":

"Y, ahora los campos, el cambio es con los alambres, porque por acá todo tiene su dueño ahora. No es como antes que todo era así nomás. Campo libre" (criancera de la zona de La Humada nacida 1941).

“Ese es otro problema... con los alambrados...Estas tierras... estos campos era todo libre [señala... pero de repente llegó a comprar gente que llegó de afuera que los cierra...Y de 
repente... gente que vivió toda una vida no... Entonces tenemos el tema de que los campos alambrados... acá un alambre no se veía!... Así que ahora tenemos ese problema vio! Entonces estamos pensado qué hacer" (productor y pastor de Chos Malal nacido en 1953).

Desde la perspectiva del estado es preocupante la situación jurídica del paraje pues es una limitante para el crecimiento de la zona, al respecto un técnico territorial aducía:

"El caso concreto es Chos Malal, donde había campos totalmente abiertos y era comunidad y cada vez queda más cercada... Eso es un gran problema... Entonces en la reunión pasada se planteó... bueno hay que ver qué hacemos acá porque la familia no puede vivir del pastoreo. Es uno de los pocos lugares donde la juventud se ha quedado... pero van cerrando, son más habitantes y menos espacio... hay que pensar en otras actividades o producir forrajes para esos animales" (coordinador del programas productivos).

La revalorización del espacio y el nuevo avance de la frontera productiva hacia los espacios de borde suponen un proceso de "acorralamiento" de las familias que se produce en tres direcciones. Por un lado, desde el este pampeano, dado el corrimiento de las isohietas y el desplazamiento del ganado vacuno (causado por el avance de la agricultura en la llanura oriental) hacia el monte occidental y recientemente el avance de los cotos de caza. Asimismo, desde el sur del departamento Puelén, el avance productivo se asocia con el reciente descubrimiento de petróleo en la zona, perteneciente al borde septentrional de la cuenca neuquina. Desde el oeste, es decir en el sector mendocino, la frontera productiva se desplaza con la producción vacuna y caprina. De este modo, en los últimos diez años se están produciendo diferentes modificaciones en la organización espacial que implican los siguientes procesos de cambio de tipo productivos y socio-territoriales:

- Parcelamiento de los predios con alambrado. Los alambres avanzan en el perímetro de la región que bordea a ambas zonas de estudio, en espacios -llamados "campos libres"- donde antes se pastoreaba a los animales y se utilizaba el "talaje". Se han registrado conflictos cuando los animales de los campesinos han ingresado en esa explotación en la que reside un empleado y se dificulta la devolución, práctica que entre campesinos era habitual.

- Disminución de la superficie de pastoreo. Como consecuencia del parcelamiento de los campos se está achicando la superficie de pastoreo común, lo que supone un incremento de la presión sobre el suelo y la sobreexplotación del monte. Al mismo tiempo, demanda nuevos requerimientos de alimentos alternativos. Asimismo, está alterándose la forma de reproducción de los animales ya que se vuelve cada vez más necesario adquirir reproductores, que en el pasado, con el campo abierto y el intercambio de ganado limitaba la consanguinidad. El achicamiento de los campos y menor talaje puede generar en el corto plazo enfrentamientos entre vecinos. La diferencia en la cantidad de animales de las familias está produciendo tensiones entre los que más caprinos tienen y los que menos, pues los acusan de quitar espacio de pastoreo al resto.

- Sobrecarga de los campos con vacunos. La menor superficie obliga se traduce en una intensificación del el uso del monte disponible, volviéndose la producción vacuna una alternativa sólo para los productores más acomodados, pues deja mayores ingresos que la caprina. Este proceso se está produciendo especialmente en La Humada donde las condiciones socioeconómicas de los productores permiten el acceso y manejo de este tipo 
de ganado. Al mismo tiempo, la sobrecarga de los campos con vacunos es generada por nuevos compradores quienes, por lo general, por provenir de otros espacios desconocen la receptividad del campo.

- Menor acceso a los recursos del monte. En relación con los dos anteriores procesos, el achicamiento de los campos reduce las actividades de caza y recolección llevadas a cabo por los grupos domésticos para la obtención de alimentos para el autoconsumo, insumos para la producción pastoril-artesanal y productos intercambiables (pieles, plumas, huevos, ramas, entre otros) que posibilitan la generación de ingresos extras. Asimismo, las nuevas legislaciones protectoras de la fauna silvestre -la ley 1194- restringen la actividad de caza de subsistencia.

- Corte e interrupción de caminos y/o acceso al agua._Las inversiones de empresas y privados en los lotes que bordean a las zonas de estudio, están produciendo el cierre de caminos irregulares (huellas) que unen puestos y ojos de agua. El proceso se manifestó recientemente en el sur de la zona de Chos Malal cercana a la localidad de Puelén, donde foráneos, empresas forestales o petroleras han adquirido la compra por compra diversos lotes. En este marco a determinadas familias se les ha impedido acceder a sus puestos $o$ bien se les han encerrado las aguadas o se les ha limitado la circulación con amenazas y uso de violencia.

- Conflictos y solidaridades entre vecinos. Ante los procesos de cambio productivo y territorial mencionados están creciendo las confrontaciones por el uso de los recursos, especialmente, en los espacios de pastoreo de uso colectivo entre diferentes familias. Este proceso que se está gestando en la región tiene un desarrollo similar en otros espacios donde el avance productivo se ha generado con anterioridad o a un ritmo más acelerado como en el norte cordobés, en el chaco salteño o en la patagonia septentrional.

De este modo, el progresivo cercamiento de los recursos naturales compromete la reproducción campesina porque limita el despliegue de aquellas actividades productivas que en el pasado completaban las canastas de alimentos, insumos y bienes intercambiables a disposición de las unidades domésticas (Comerci, 2012a). Los alambrados crean interferencias en la ecuación tierras-pasturas-agua, obstruyen la flexibilidad que deben mantener los sistemas agro-pastoriles para acomodarse a las incertidumbres y limitan el desplazamiento a través de recursos naturales irregularmente distribuidos (Torres et al., 2014). El alambrado, expresión más clara de la lógica territorial de la propiedad privada, desarticula la territorialidad campesina creada en torno a los acuerdos de palabra por el control del espacio de pastoreo y el uso compartido del monte e impone una nueva dinámica territorial que pone en jaque la capacidad de reproducción de estos grupos.

\section{Últimas consideraciones}

El relevamiento del sistema de asentamientos de puestos que expresa formas de organización de las territorialidades campesinas es de vital importancia para poder comprender los esquemas de uso, apropiación y significados territoriales para las familias rurales de espacios áridos de la Argentina. A pesar del avance de la lógica empresarial persisten productores familiares que presentan transformaciones de la unidad doméstica, en el espacio rural y en las representaciones 
(Bendini y Steimbreger, 2013). El concepto de territorialidad campesina permite representar el complejo caudal de estrategias que al campesinado le permiten resistir y permanecer en condiciones agro-ecológicas y socio-institucionales históricamente desventajosas y en contextos de expansión concentrada del capital (Torres et al., 2014).

En el caso de estudio, las lógicas de organización del espacio creadas por el Estado y luego por el capital, expresadas en la cartografía catastral y en la división de los predios, han diferido de los patrones de construcción y organización del espacio realizado por los puesteros. Por un lado, se encuentran las territorialidades producidas desde "afuera" de la región, centralizadas en el este provincial, surgidas en el contexto de la formación del Estado-nación y la incorporación de los territorios en dominio indígena al mercado inmobiliario. De este modo, mediante diferentes políticas públicas se construyeron geométricas picadas y rutas reproduciendo el perfecto trazado en damero, se realizaron viviendas similares a las diseñadas para los ámbitos urbanos de la capital o se delimitaron las explotaciones con alambrados.

Estas territorialidades controladas y dominadas, coexistieron con otras, internas, heterogéneas, singulares, y construidas por los sujetos que han habitado el lugar. Rasgos de esta lógica diferencial de pensar y construir lo espacial y producir territorialidades, se expresan actualmente a diferentes escalas geográficas: en la organización interna del puesto (conformado por el espacio doméstico, peridoméstico y el monte abierto), en los patrones de distribución y localización de los puestos a escala regional -en función del acceso a los recursos naturales, las relaciones jurídicas con la tierra y las redes parentales-comerciales asociadas con la región cuyana-patagónica- así como en las singulares denominaciones y sentidos de lugar que los sujetos atribuyen a los puestos.

El monte ha constituido a través del tiempo, un espacio de vida fundamental para la supervivencia de las familias. Además de ofrecer pasturas y aguadas naturales para el ganado, ha garantizado el desarrollo de múltiples actividades de recolección y caza que aportan alimentos, insumos a la producción artesanal o productos para el intercambio. Este recurso estratégico para los grupos domésticos campesinos ha tenido un manejo colectivo acordado entre familias que ha dado origen a una territorialidad gestada desde hace más de un siglo y que el avance del capital con el cercado está alterando.

Estos procesos socio-productivos, sumados a otros asociados con la mayor articulación con los pueblos y la vida urbana, la acción de nuevos agentes intermediarios y mayor importancia de los ingresos públicos, alteran las prácticas productivas-reproductivas, redefinen las estrategias de vida de los crianceros y las posiciones en el mapa de poder regional. Procesos y escenarios sociales que dan cuenta de la nueva configuración del agro argentino en los espacios de borde: dominada por las territorialidades del capital versus las territorialidades campesinas y por las distintas estrategias de adaptación y/o resistencia generadas por los sujetos en torno a esas tensiones.

\section{Referencias bibliográficas}

AGNEW, J. Place and politics: the geographical mediation on state and society. Boston: Allen and Unwin, 1987. 
BEDOTTI, D.; GOMEZ CASTRO, A.; SANCHEZ, M.; GARCIA, A. y MARTOS, J. Aspectos sociológicos de los sistemas de producción caprina en el oeste pampeano (Argentina). Archivos de Zootecnia, 2005, Vol. 54, N²08, p. 599-608.

BENDINI, M. y STEIMBREGER, N. Territorialidad campesina en el sur de Argentina. Cambios productivos y laborales como formas de resistencia. Revista Eutopía, 2013, № 4, p. 25-44.

COMERCI, M.E. Tenemos que ir allá y pegar la vuelta. Continuidades y cambios en las prácticas de movilidad campesinas en contextos de conflictividad emergente. Revista Transporte y Territorio, 2010, $N^{\circ} 3$, p. 72-102.

COMERCI, M.E. Estrategias campesinas, tensiones y redefiniciones en espacios revalorizados por el capital. Revista Cuadernos de Geografía, № 21, 2012a, p.131-146.

COMERCI, M.E. Espacios y tiempos mediados por la memoria. La toponimia en el Oeste de La Pampa en el siglo XX. Revista Corpus. Archivos virtuales de la alteridad americana, 2012b, Vol. 2, $N^{\circ}$ 2. Disponible en Internet: https://corpusarchivos.revues.org/816

COMERCI, M.E. Territorialidades en el campo argentino: Geografías, procesos y sujetos. Santa Rosa: EdUNLPam, 2015.

GÖBEL, B. La arquitectura del pastoreo: uso del espacio y sistema de asentamientos en la puna de Atacama (Susques). Estudios Atacameños, 2002, N²3, p. p. 53-76.

HAESBAERT, R. El mito de la desterritorialización. Río de Janeiro: Bertrand, 2004.

HOCSMAN, L. Estrategias territoriales, recampesinización y etnicidad en los andes de Argentina. México D.F.: Universidad Autónoma Metropolitana, 2011.

LEFEBVRE, H. La produccion del 'espace. Paris: Antropos, 1974.

MAMMANA, E. Cuarto operativo de la Misión Salesiana en el Oeste Pampeano. En: Capilla de Padre Buodo. Rescate de C. Salomón Tarquini, 1972.

ORDOÑEZ, F. Territorialidades alternativas a las del capital en Colombia. El caso de la Zona de Reserva Campesina del Valle del río Cimitarra. Instituto Latinoamericano para una Sociedad y un Derecho Alternativos, 2011. Disponible en Internet: http://www.rimisp.org/wp-content/ uploads/2013/03/16.pdf

PODUJE, M. Viviendas Tradicionales en la Provincia de La Pampa. Santa Rosa: Gobierno de la Provincia de La Pampa, Departamento de Investigaciones Culturales,2000.

RAFFESTIN, C. Por una geografía del poder. México: El Colegio de Michoacán, [1980], 2011.

TOMASI, J. Transformaciones urbanas y vivienda en Susques, Jujuy. En: Seminario de Crítica, Instituto De Arte Americano, San Salvador De Jujuy, 2005. Disponible en Internet: http://www.iaa.fadu. uba.ar/publicaciones/critica/0149.pdf. 
TOMASI, J. El lugar de la construcción: prácticas y saberes en la puna argentina. Cuadernos de la Facultad de Humanidades y Ciencias Sociales. Universidad Nacional de Jujuy, 2009, №36, p. $141-157$

TORRES, L.; PESSOLANO, D. y MORENO, M. Transformaciones territoriales y reproducción social del campesinado en espacios extra-pampeanos de tierras secas (Argentina). Aportes para el debate. Revista Interdisciplinaria de Estudios Agrarios, 2014, № 40, p. 37-76. 
